\title{
MicroRNA-133a inhibits cell proliferation, colony formation ability, migration and invasion by targeting matrix metallopeptidase 9 in hepatocellular carcinoma
}

\author{
$\mathrm{XIAN} \mathrm{CHEN}^{1}$, LIANHUA BO $^{1}, \mathrm{XUE} \mathrm{ZHAO}^{1}$ and $\mathrm{QI} \mathrm{CHEN}^{1,2}$ \\ Departments of ${ }^{1}$ Infectious Diseases and ${ }^{2}$ Urology, The Fourth Affiliated Hospital of Nantong Medical College, \\ Yancheng No. 1 People's Hospital, Yancheng, Jiangsu 224001, P.R. China
}

Received April 21, 2014; Accepted December 19, 2014

DOI: $10.3892 / \mathrm{mmr} .2015 .3232$

\begin{abstract}
MicroRNA-133a (miR-133a) is downregulated in various types of human malignancy, including hepatocellular carcinoma (HCC), renal cell carcinoma, esophageal squamous cell carcinoma, bladder cancer, ileal carcinoid and rhabdomyosarcoma. The aim of the present study was to examine the effects of miR-133a on HCC cell proliferation, colony formation, migration and invasion. miR-133a was transfected into the HCC HepG2 and SMMC-7721 cell lines and the expression levels of miR-133a were determined; in addition, cell viability assays, colony formation assays, cell migration assays, cell invasion assays, western blot analyses and luciferase assays were performed in the HCC cell lines. The results demonstrated that miR-133a significantly inhibited cell proliferation, colony formation, migration and invasion in HepG2 and SMMC-7721 cells. To the best of our knowledge, the present study also provided the first evidence that miR-133a directly downregulated the expression of matrix metallopeptidase 9 (MMP-9) in the HCC cells. In conclusion, the results of the present study indicated that miR-133a may have suppressed cell proliferation, colony formation, migration and invasion via the downregulation of MMP-9 in HCC cell lines. Therefore, MMP-9 may be used for the development of novel molecular markers and therapeutic approaches to inhibit hepatocellular carcinoma metastasis.
\end{abstract}

\section{Introduction}

Types of primary liver cancer include hepatocellular carcinoma (HCC), intrahepatic cholangiocarcinoma (ICC) and hepatic

Correspondence to: Professor Qi Chen, Department of Urology, The Fourth Affiliated Hospital of Nantong Medical College, Yancheng No. 1 People's Hospital, 15 Yuehe Road, Yancheng, Jiangsu 224001, P.R. China

E-mail: wudeyao_850405@163.com

Key words: hepatocellular carcinoma, matrix metallopeptidase-9, microRNA-133a angiosarcoma. HCC accounts for between 85 and $90 \%$ of all cases of primary liver cancer and is the third leading cause of mortality from cancer worldwide and the fifth most common type of malignancy (1-4). It has been reported that 21,000 cases of HCC are diagnosed and $\sim 700,000$ patients succumb to the disease worldwide annually (5). The established risk factors of HCC include viral hepatitis, alcohol abuse and non-alcoholic fatty liver disease (6). For the majority of patients with HCC, surgical resection and liver transplantation are the only effective treatment options; however, only between 10 and $20 \%$ of patients are eligible for surgical intervention, due to the difficulty in effectively diagnosing HCC in the early stages of the disease (7). Frequent tumor metastasis and recurrence following surgical intervention lead to poor prognoses of patients with HCC with a five-year survival rate of $\sim 5 \%$ (8). Advances in functional genomics have provided a deeper understanding of hepatocarcinogenesis; however, the molecular pathogenesis of HCC remains to be fully elucidated $(9,10)$. In addition, the clinical heterogeneity of HCC and insufficient effective diagnostic markers and therapeutic approaches for the treatment of HCC have rendered this disease a major challenge (11). Therefore, in order to improve the prognosis of patients with HCC, novel diagnostic markers and treatments are required.

MicroRNAs (miRNAs) are a type of small, endogenous, single-stranded, non-coding RNA, which consist of between 20 and 25 bases (12). miRNA was first detected during a developmental timing experiment, which was performed in the nematode Caenorhabditis elegans in 1993 (13). To date, the family of human miRNAs consists of $>2,000$ mature miRNAs and, using in silico techniques, it was predicted that $\sim 60 \%$ of human messenger (m)RNA may be targets of miRNAs (14). In addition, miRNAs abberrantly expressed in several types of human cancer may function as oncogenes and tumor suppressors (15). Based upon a large number of experimental studies performed over the past two decades, it has been confirmed that miRNAs are important in the regulation of gene expression, which primarily occurs through post-transcriptional destabilization, translational repression of target mRNAs which bear complementary sites or a combination of these two mechanisms (16-19).

Previous studies have demonstrated that miRNAs are essential in the biology of various types of human cancer, 
including cell differentiation, proliferation, apoptosis, invasion and angiogenesis $(20,21)$. It was reported that $\geq 17$ miRNAs are downregulated in HCC, while six miRNAs are upregulated(22). miRNAs which are upregulated in cancer may function as oncogenes through the negative regulation of tumor suppressors. By contrast, miRNAs which are downregulated in cancer may normally function as tumor suppressor genes, which inhibit cancer through the regulation of oncogenes (23). Therefore, the identification of miRNA targets is critical in order to fully elucidate the function of miRNAs in the development and progression of cancer. In addition, it has been suggested that miRNAs may be potential target for the treatment of cancer (24).

It has been reported that miRNA (miR)-133a is among the most frequently downregulated miRNAs in various types of human malignancy, including HCC (25), renal cell carcinoma (26), esophageal squamous cell carcinoma (27), bladder cancer (28), ileal carcinoid (29) and rhabdomyosarcoma (30). The aim of the present study was to determine the effects of miR-133a on cell proliferation, colony formation, migration and invasion in HCC HepG2 and SMMC-7721 cell lines, as well as to investigate whether matrix metallopeptidase 9 (MMP-9) may be a target of miR-133a.

\section{Materials and methods}

Cells and culture conditions. The human HCC cell lines, HepG2 and SMMC-7721, were obtained from the Shanghai Institute Of Biochemistry And Cell Biology (Shanghai, China). The HepG2 and SMMC-7721 cells were cultured in RPMI 1640 medium (Gibco, Grand Island, NY, USA) supplemented with $10 \%$ heat-inactivated fetal bovine serum (FBS; Gibco) under a humidified atmosphere of $5 \% \mathrm{CO}_{2}$ at $37^{\circ} \mathrm{C}$. To propagate sphere formation in vitro, spheres were collected through gentle centrifugation at $200 \mathrm{x}$ g for $5 \mathrm{~min}$, dissociated to single cells by blowing gently and cultured in RPMI-1640 to produce the next generation of spheres.

Transfection. Mature miR-133a mimics and negative control (NC) miRNA mimics were designed and synthesized by GenePharma(Shanghai,China).The sequences were asfollows: miR-133a mimic, 5'-UUUGGUCCCCUUCAACCAGCUG-3' and NC mimic, 5'-UUCUCCGAACGUGUCACGUTT-3'. The cells were transfected using Lipofectamine 2000 (Invitrogen Life Technologies, Carlsbad, CA, USA), according to manufacturer's instructions.

Quantitative detection of miR-133a. Total RNA was extracted from the cells using TRIzol reagent (Invitrogen Life Technologies) in a one-step extraction procedure, as previously described (31). RNA was stored in diethylpyrocarbonate-treated water at $-80^{\circ} \mathrm{C}$ and the quantity and quality of samples were evaluated using a ND-1000 NanoDrop spectrophotometer (NanoDrop, Wilmington, DE, USA). Reverse transcription quantitative polymerase chain reaction (RT-qPCR) for miR-133a was performed using a SYBR Green miRNA assay (GenePharma), according to the manufacturer's instructions. qPCR was performed on an AB7300 thermo-recycler (Applied Biosystems, Waltham, MA, USA) using miR-133 primer set (Tiangen Biotech, Co., Ltd, Beijing,
China) and double strand binding dye SYBR Green. GAPDH was used as an internal control. Each sample was replicated three times, with no RT or template control included. Data were analyzed by comparing $\mathrm{Ct}$ values (32).

3-(4, 5-dimethylthiazol-2-yl)-2,5-diphenyltetrazolium bromide (MTT) assay. Cell proliferation was determined using a MTT Cell Proliferation and Cytotoxicity Assay kit (Beyotime Institute of Biotechnology, Shanghai, China). The transfected cells (miR-133a mimics and NC) were seeded into 96-well flat-bottomed plates (Becton-Dickinson, Heidelberg, Germany) at a density of 3,000 cells per well. Every $24 \mathrm{~h}$ for 5 days, the viable cells were assayed for their ability to transform MTT into purple formazan, and their optical density was measured at $490 \mathrm{~nm}(\mathrm{OD})_{490}$. The suppression rate was calculated using the following formula: Suppression rate $=\left(1-\mathrm{OD}_{\mathrm{miR}-145} / \mathrm{OD}_{\mathrm{miR}-\mathrm{NC}}\right) \times 100 \%$. Proliferation curves were drawn on the basis of the mean absorbance at each time-point. All experiments were performed in triplicate.

Colony formation assay. The colony formation ability of the miR-133a-transfected HepG2 and SMMC-7721 cells was assessed using a colony formation assay. In brief, the transfected cells (miR-133a mimics and NC) growing in the logarithmic phase were trypsinized with $0.05 \%$ Trypsin-EDTA (Gibco) and seeded into six-well plates at a density of 2,000 cells per well. The cells were maintained in an incubator at $37^{\circ} \mathrm{C}$ for 7 days. On day 8, the colonies were washed with phosphate-buffered saline (PBS), fixed with formalin (10\%), and stained with methyl violet, which were all purchased from Beyotime Institute of Biotechnology. The methyl violet dye was then washed with PBS and the number of colonies were counted under a microscope (IX53; Olympus Corp., Tokyo, Japan). The following calculations were then performed: Colony-inhibition rate $=[(1-$ number of colonies in experimental groups) / control group $\times 100 \%$; and colony-forming efficiency $=1$ - colony-inhibition rate.

Cell migration and invasion assay. The cell migration and invasion were assayed using Transwell ${ }^{\circledR}$ chambers $(8 \mu \mathrm{m}$; Corning Costar, Cambridge, MA, USA). For the Transwell ${ }^{\circledR}$ migration assay, $1 \times 10^{5}$ transfected cells (miR 133a mimics and NC) were placed into the upper chamber, which was cultured in medium with $2 \%$ FBS, while $500 \mu$ l RPMI-1640 medium containing $20 \%$ FBS was added to the lower chamber. For the Transwell ${ }^{\circledR}$ invasion assay, a Transwell ${ }^{\circledR}$ chamber coated with Matrigel ${ }^{\circledR}$ (BD Biosciences, San Jose, CA, USA) and a total of $1 \times 10^{5}$ cells were seeded into the upper chamber, while the lower chamber was incubated with $500 \mu \mathrm{l}$ RPMI-1640 medium containing $20 \%$ FBS. The cells were incubated under a humidified atmosphere of $5 \% \mathrm{CO}_{2}$ at $37^{\circ} \mathrm{C}$ for $12 \mathrm{~h}$ for the migration assay and $24 \mathrm{~h}$ for the invasion assay. Subsequently, cells remaining in the upper chambers or on the upper membrane of the inserts were carefully removed with cotton swabs. Following fixation and staining in a dye solution containing $0.5 \%$ crystal violet (Beyotime Institute of Biotechnology) and 20\% methanol (Macklin Biochemical Co., Ltd, Shanghai, China), the cells adhering to the lower membrane of the inserts were counted and imaged with microscopy (magnification, x200). 
Five five fields of vision for each insert were randomly selected and counted under a light microscope (IX53; Olympus Corp.). Each condition was assayed in triplicate and each experiment was repeated a minimum of three times.

Target of miR-133b. In order to determine whether miR-133a targets the MMP-9 3'-UTR, TARGETSCAN 5.2 (http://www. targetscan.org/) and PICTAR (http://pictar.mdc-berlin.de/) were used.

Western blot analysis. The transfected cells (miR-133a mimics and NC) were washed with ice-cold PBS and lysed with $1 \%$ radioimmunoprecipitation assay lysis buffer (Beyotime Institute of Biotechnology) $72 \mathrm{~h}$ after transfection. The supernatants were collected and the protein concentrations were determined using a Bicinchoninic Acid Assay kit (Beyotime Institute of Biotechnology). Equal quantities of the proteins were separated and analyzed using 10\% SDS-PAGE (Beyotime Institute of Biotechnology) and then transferred onto polyvinylidene difluoride membranes (Beyotime Institute of Biotechnology). The membranes were then blocked with $5 \%$ skimmed milk (Shyuanmu, Shanghai, China), followed by incubation overnight at $4^{\circ} \mathrm{C}$ with a primary rabbit anti-human polyclonal MMP-9 antibody (1:1,000; Bioworld Technology, Inc., St. Louis Park, MN, USA), according to the manufacturer's instructions. The membranes were then washed three times with Tris-buffered saline with $1 \%$ Tween 20 (TBST; Beyotime) and then incubated at room temperature with the corresponding horseradish peroxidase-conjugated goat anti-rabbit secondary antibody $(1: 1,000)$ in TBST. Western blots were developed using enhanced chemilluminescence solution (Pierce Biotechnology, Inc., Rockford, IL, USA) and images were captured using a FluorChem imaging system (Alpha Innotech Corp., San Leandro, CA, USA). The data were normalized to $\beta$-actin.

Luciferase assay. The HepG2 and SMMC-7721 cells were transfected with $0.5 \mu \mathrm{g}$ reporter plasmid, $40 \mathrm{nmol}$ miR-133a mimics or NC in a 12-well plate using Lipofectamine 2000, according to manufacturer's instructions. The assays were performed using the Dual-Luciferase Reporter Assay system (Promega Corporation, Manheim, Germany) $48 \mathrm{~h}$ after transfection. The activities of Firefly and Renilla luciferase were measured using a luminometer (Tecan Group, Ltd, Maennedorf, Switzerland). The firefly luciferase activity was normalized to that of the Renilla luciferase for each transfected well. Each reporter plasmid was transfected a minimum of three times (on different days) and each sample was assayed in triplicate.

Statistical analysis. Data are presented as the mean \pm standard deviation and were compared using the Student's t-test using Stata 10.0 software (StataCorp LP, College Station, TX, USA). $\mathrm{P}<0.05$ was considered to indicate a statistically significant difference.

\section{Results}

Expression of miR-133a prior to and following transfection of miR-133a mimics in HepG2 and SMMC-7721 cells. The endogenous levels of miR-133a in the HepG2 and
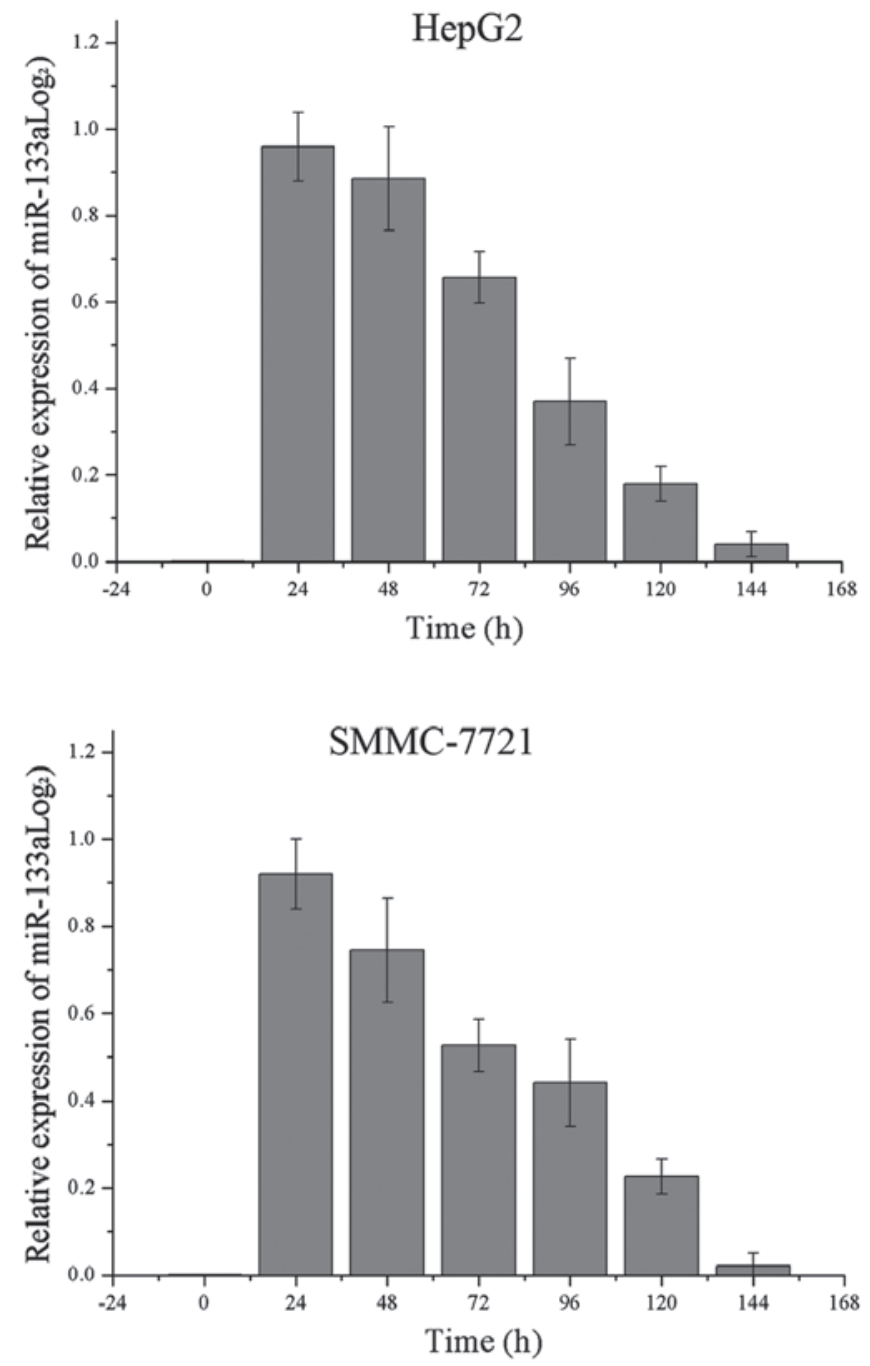

Figure 1. Expression of miR-133a in HepG2 and SMMC-7721 hepatocellular carcinoma cells. The expression of miR-133a was markedly increased until $144 \mathrm{~h}$ following transfection with miR-133a. Values are presented as the mean \pm standard deviation. miR-133a, microRNA-133a.

SMMC-7721 cells, and its expression following transfection with miR-133a, was determined every $24 \mathrm{~h}$. As expected, the basal expression of miR-133a was too low to be shown in Fig. 1. However, following transfection with miR-133a, the expression levels of miR-133a were markedly increased compared with those of the untransfected cells at $24 \mathrm{~h}$, until $144 \mathrm{~h}$. Of note, the expression of miR-133a decreased in a time-dependent manner from $24 \mathrm{~h}$.

miR-133a reduces the proliferation and colony formation abilities of HepG2 and SMMC-7721 cells. In order to investigate the effect of miR-133a on cell proliferation, an MTT assay was performed. The results demonstrated that upregulation of miR-133a significantly inhibited cell proliferation compared with the NC-transfected cells (Fig. 2A). In addition, the MTT assays revealed that after $144 \mathrm{~h}$ of treatment, the suppression rate of miR-133a reached $35.80 \pm 3.2 \%$ in the HepG2 cells and $41.15 \pm 3.6 \%$ in the SMMC-7721 cells.

In order to investigate the effect of miR-133a on colony formation in theHCC cells, a colony formation assay was 

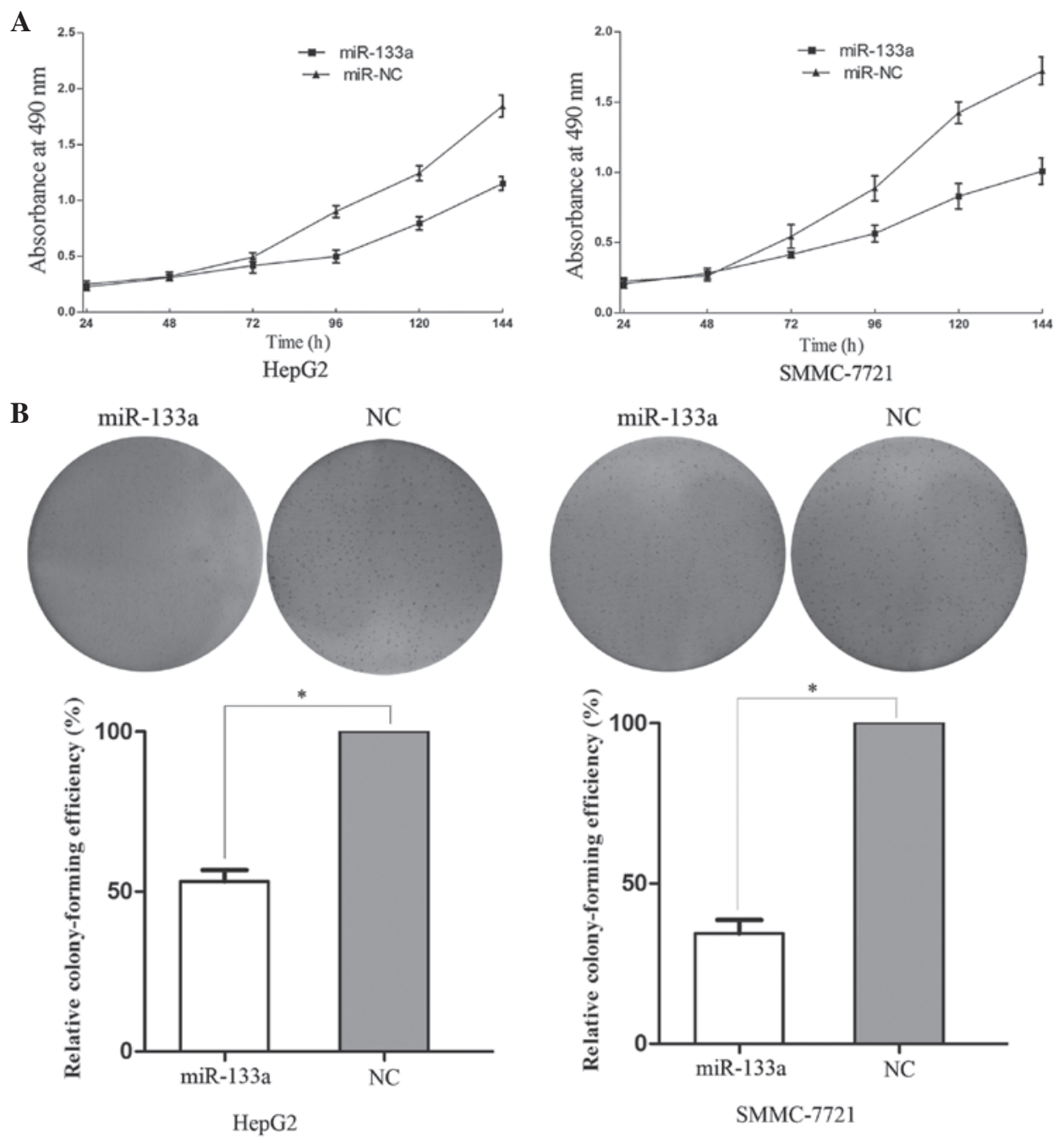

Figure 2. Cell proliferation and colony forming ability of HepG2 and SMMC-7721 cells following transfection with miR-133a or miR-NC. (A) 3-(4, 5-dimethylthiazol-2-yl)-2,5- diphenyltetrazolium bromide assays were used to determine cell proliferation in the HCC cell lines. Upregulation of miR-133a significantly suppressed cell proliferation in the HepG2 and SMMC-7721 cells compared with that in the cells transfected with miR-NC. (B) miR-133a inhibited cell colony formation in HCC cells. A total of 2,000 transfected cells (miR-133a and $\mathrm{NC}$ ) were plated onto six-well plates. On day 8, the cells were fixed with formalin and stained with methyl violet to reveal colony formation. The upregulation of miR-133a significantly suppressed colony formation in the HepG2 and SMMC-7721 cell lines. Values are presented as the mean \pm standard deviation. ${ }^{*} \mathrm{P}<0.05$ vs. NC-transfected cells. miR, microRNA; HCC, hepatocellular carcinoma; NC, negative control.

performed. As shown in Fig. 2B, the relative colony-formation efficiency of the miR-133a-transfected cells was $53.2 \pm 4.5 \%$ in the HepG2 cells and $34.4 \pm 5.9 \%$ in the SMMC-7721 cells, compared with the cells transfected with the $\mathrm{NC}(\mathrm{P}<0.05)$. Overall, these results indicated that miR-133a may be important in the proliferation and colony formating ability of HCC HepG2 and SMMC-7721 cells.

miR-133a suppresses cell migration and invasion in HCC HepG2 and SMMC-7721 cells. In order to measure the effect of miR-133a on tumor cell migration and invasion, a Transwell ${ }^{\circledR}$ apparatus assay was performed. The results of the migration assay demonstrated that migration was significantly decreased in the miR-133a-transfected groups to $48.25 \pm 5.39 \%$ in the HepG2 cells and $58.46 \pm 6.21 \%$ in the SMMC-7721 cells compared with those of the NC-transfected groups $(\mathrm{P}<0.05$; Fig. 3A). In the invasion assay (Fig.3B), miR-133a-transfection induced a $58.35 \pm 7.89 \%$ decrease in the number of invasive HepG2 cells and a $63.12 \pm 6.52 \%$ decrease in the number of invasive SMMC-7721 cells compared with the NC-transfected cells $(\mathrm{P}<0.05)$. These results indicated that the overexpression of miR-133a reduced the migration and invasion abilities of the HCC cell lines.

MMP-9 is downregulated following overexpression of miR-133a in HCC cells. Western blot analysis was performed in order to determine whether the protein expression of MMP-9 was altered following transfection with miR-133a mimics in the HCC HepG2 and SMMC-7721 cell lines. As shown in Fig. 4, MMP-9 was significantly downregulated in the HCC HepG2 and SMMC-7721 cell lines following overexpression of miR-133a compared with the NC-transfected cells $(\mathrm{P}<0.05)$. These results indicated that miR-133a may reduce the protein level of MMP-9 in HCC cells.

MMP-9 is a direct target gene of miR-133a in HCC. To determine whether miR-133a targets the MMP-9 3'-untranslated region (UTR), TARGETSCAN 5.2 and PICTAR were 
A

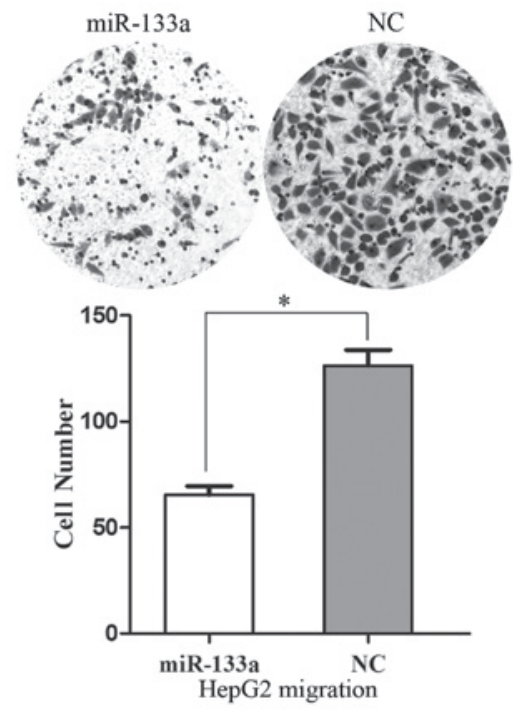

B

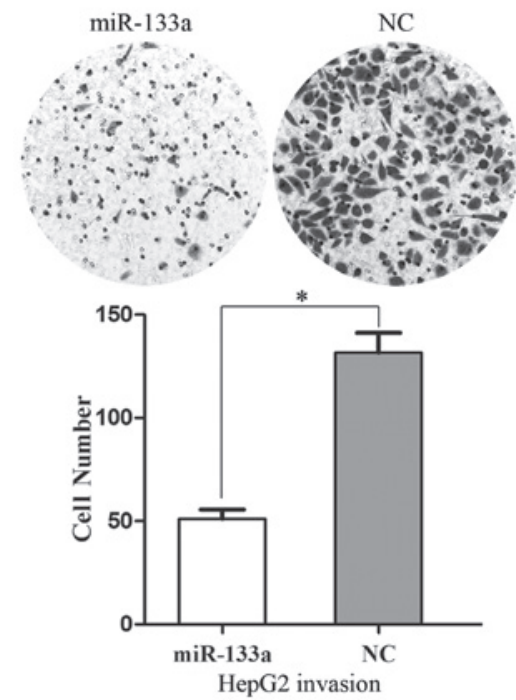

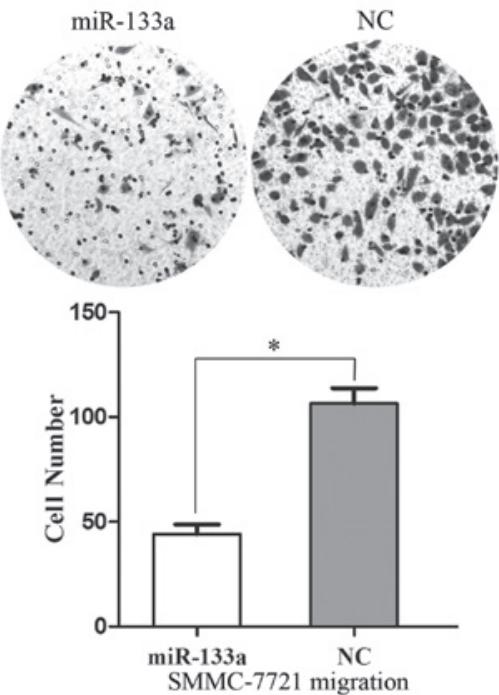

SMMC-7721 migration

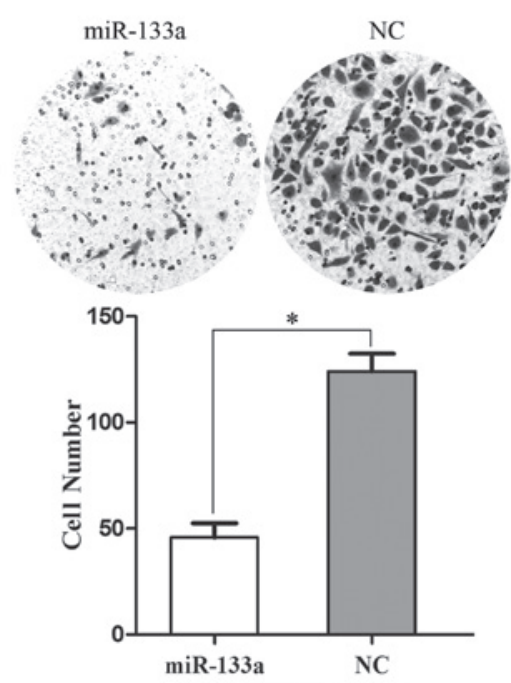

SMMC-7721 invasion

Figure 3. Cell migration and invasion of HepG2 and SMMC-7721 cells following transfection with miR-133a or miR-NC. (A) miR 133a inhibited cell migration in the HCC cell lines. After $12 \mathrm{~h}$ incubation, the number of miR-133a-transfected HepG2 and SMMC-7721 cells that transversed the Transwell ${ }^{\circledR}$ membrane were significantly decreased. (B) miR 133a inhibited cell invasion in theHCC cell lines. After $24 \mathrm{~h}$ incubation, the number of miR-133a-transfected HepG2 and SMMC-7721 cells that transversed the Transwell ${ }^{\circledast}$ membrane precoated with Matrigel were significantly decreased. Magnification, x 200 . Values are presented as the mean \pm standard deviation. ${ }^{*} \mathrm{P}<0.05$ vs. NC-transfected cells. miR, microRNA; HCC, hepatocellular carcinoma; NC, negative control.
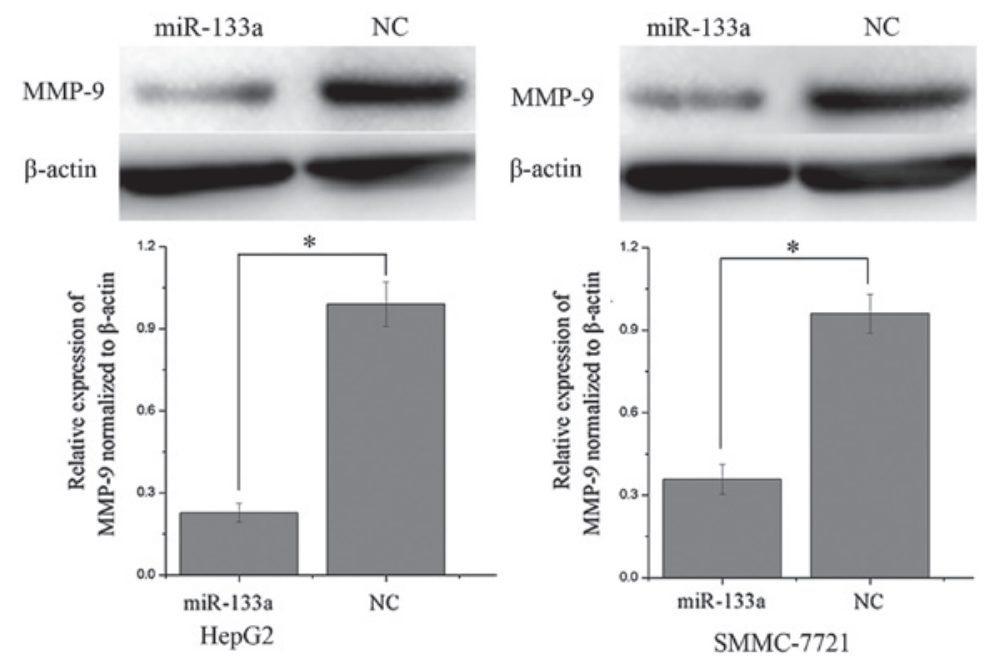

Figure 4. Western blot analysis of the protein expression of MMP-9 following transfection with miR-133a or miR-NC in the HCC cell lines. The expression of MMP-9 was significantly downregulated in the HepG2 and SMMC-7721 cells following transfection of miR-133a. Values are presented as the mean \pm standard deviation. "P<0.05 vs. NC-transfected cells. miR, microRNA; HCC, hepatocellular carcinoma; NC, negative control. 


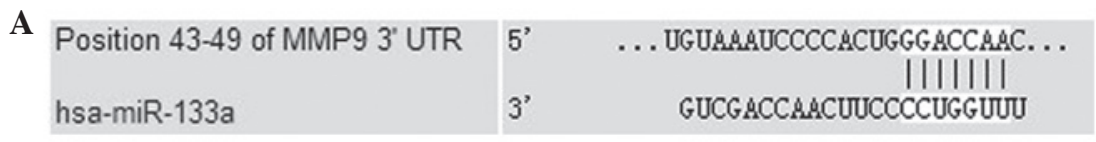

B
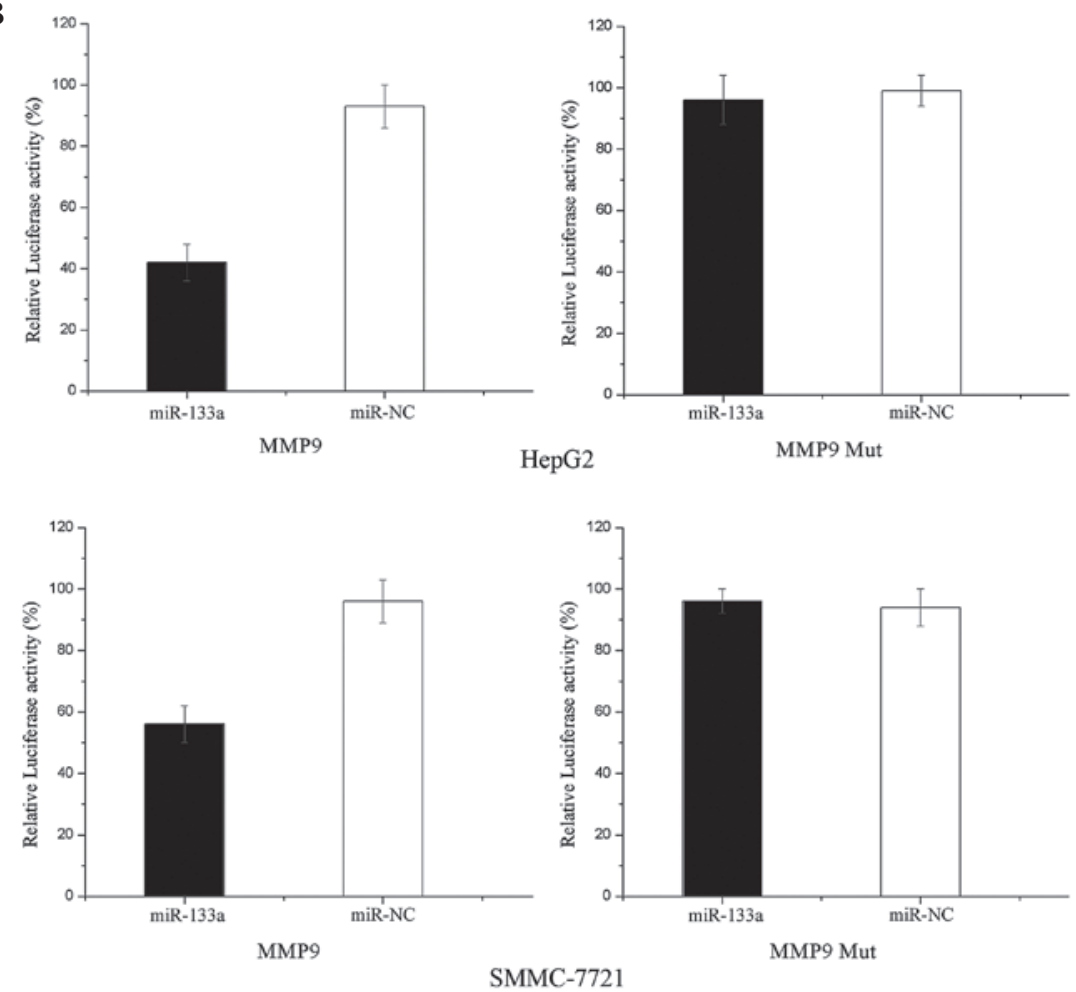

Figure 5. MMP-9 is a direct target gene of miR-133a in HCC. (A) TARGETSCAN software was used assess the complementarity of miR-133a to the MMP-9 3'-UTR, the results of which revealed that MMP-9 mRNA contained a miR-133a seven-nucleotide seed match at position 43-49 of the MMP-9 3'-UTR. (B) Luciferase reporter assays were performed in order to evaluate whether MMP-9 was a target of miR-133a in the HCC cells in vitro. Luciferase activity was reduced significantly to 55 and $42 \%$ in the HepG2 and SMMC-7721 cells, respectively, following co-transfection with miR-133a and a reporter plasmid. Values are presented as the mean \pm standard deviation. ${ }^{*} \mathrm{P}<0.05$ vs. miR-Ctrl. MMP-9, matrix metallopetidase-9; miR, microRNA; HCC, hepatocellular carcinoma; UTR, untranslated region; Ctrl, negative control.

used to assess the complementarity of miR-133a to the MMP-9 3'-UTR. It was demonstrated that MMP-9 mRNA contained an miR-133a seven-nucleotide seed match at position 43-49 of the MMP-9 3'-UTR (Fig.5A).

Luciferase reporter assays were performed to evaluate whether MMP-9 was a target of miR-133a in HCC cells. As shown in Fig. 5B, overexpression of miR-133a suppressed the activity of MMP-9 3'-UTR-luciferase by $55 \%$ in the HepG2 cells and $42 \%$ in the SMMC-7721 cells compared with the NC-transfected cells $(\mathrm{P}<0.05)$. Overall, these results indicated that MMP-9 may be a direct target of miR-133a in vitro.

\section{Discussion}

miR-133 is an miRNA family containing miR-133a and miR-133b; which differ by only one base in the terminal $3^{\prime}$ position (33). miR-133a is a multicopy gene, with two copies in chromosomes 18 and 20, which are located next to another muscle-enriched miRNA, miR-1, while miR-133b is located in chromosome 6 (34). miR-133a has been recognized as a muscle-specific miRNA, which may regulate myoblast differentiation and be involved in myogenic and heart diseases $(30,35,36)$. Furthermore, miR-133a has been commonly identified as being downregulated in various human malignancies, including hepatocellular carcinoma (25), renal cell carcinoma (26), esophageal squamous cell carcinoma (27), bladder cancer (28), ileal carcinoid (29) and rhabdomyosarcoma (30).

Identification of miR-133a target genes is essential for understanding its role in tumorigenesis and for defining novel therapeutic targets. Studies have found that miR-133a regulates oncogenic transcripts in human cells, including FSCN1, EGFR, LASP1, GSTP1 and TAGLN2 $(34,37,38)$. Therefore, upregulating miR-133a or providing exogenous analogous pharmaceutical compounds may provide effective cancer therapies for $\mathrm{HCC}$, which resulted from the overexpression of these oncogenic transcripts. The results of the present study revealed multiple inhibitory effects of miR-133a in the HepG2 and SMMC-7721 HCC cell lines, including growth arrest, reduced cell colony formation ability and suppression of migration and invasion, by downregulating the expression of MMP-9. These findings suggested that miR-133a may be used for the development of novel molecular markers and therapeutic approaches for the inhibition of metastasis in HCC.

The incidence of HCC is increasing in several countries and is becoming one of the most prevalent types of terminal cancer worldwide (39). In addition, HCC is characterized by rapid progression, early metastasis and frequent recurrence (40). Despite improvements in the diagnosis and 
treatment of HCC, however, it remains an aggressive type of cancer with a poor prognosis. Tissue invasion and metastasis are the primary cause of mortality in patients with HCC (40). Defining the mechanisms regulating HCC invasion may identify novel elements, which may be exploited therapeutically to reduce metastasis and improve patient survival. The process of metastasis involves several steps, including the detachment of cancer cells from the primary tumour, followed by the migration, adhesion and invasion of cancer cells into blood or lymphatic vessels; cancer cells then undergo extravasation and subsequently interact with target tissues, where they form metastastic foci in distant organs (41). The destruction of the extracellular matrix (ECM) by enzymes is an essential initial step in the processes of tumor cell invasion and metastasis, and several studies have reported that, among the enzymes responsible for ECM degradation, MMPs are have a critical role $(42,43)$.

MMPs are a family of zinc-dependent endopeptidases, which have share several structural and functional properties, but with different substrate specificities (44). MMPs are important in various physiological processes, which include tissue remodeling, organ development, angiogenesis, inflammatory processes, vascular and autoimmune disorders and cancer (45). In addition, MMPs are upregulated in various types of human malignant tumor. The majority of clinical data had revealed correlations between the expression of MMPs and advanced tumor stages, invasion, metastasis and decreased survival rates (46). Previous studies have demonstrated that several MMPs are overexpressed in HCC and that high expression levels of MMPs are associated with cancer progression and metastasis (47-49). It was therefore suggested that inhibitors of MMP activity may be investigated for the prevention or reduction of tumor metastasis.

A total of 24 soluble and membrane-anchored members of the MMP family have been identified, which are subdivided into four families based on structure and substrate specificity as follows: Collagenases, gelatinases, stromelysins and membrane-associated MMPs (50). Among these MMPs, the activities of MMP-2 and -9 have been associated with the progression of HCC $(48,51)$. In addition, these studies revealed an association between the overexpression of MMP-2 or -9 and the invasion and metastasis of HCC. Increased levels of MMP-9 in HCC also correlate with increased tumour recurrence and metastasis following resection $(48,49,52)$. Hayasaka et al (53) reported that MMP-9 plasma levels were upregulated in HCC patients, particularly in patients who presented with macroscopic portal vein invasion, which suggested that MMP-9 may serve as a marker for transformation and invasion in $\mathrm{HCC}$ or as a therapeutic target for the inhibition of metastasis in HCC. The results of the present study suggested that miR-133a suppressed $\mathrm{HCC}$ cell migration and invasion via the downregulation of MMP-9, therefore indicating the predictive value of MMP-9 for early detection of tumor metastasis and as a target for preventative therapies to inhibit HCCs becoming invasive.

In conclusion, to the best of our knowledge, the present study was the first to demonstrate that miR-133a inhibited HCC cell proliferation, colony formation, migration and invasion by downregulating the expression of MMP-9. These findings have therapeutic implications and may be exploited for further treatment of HCC. Further studies are required to determine whether the potential of miR-133a may be fully realized in cancer treatment.

\section{References}

1. Kudo M: Hepatocellular carcinoma in 2011 and beyond: from the pathogenesis to molecular targeted therapy. Oncology 81 (Suppl 1): $1-10,2011$.

2. Meguro M, Mizuguchi T, Kawamoto M and Hirata K: The molecular pathogenesis and clinical implications of hepatocellular carcinoma. Int J Hepatol 2011: 818672, 2011.

3. Yamazaki K, Masugi Y and Sakamoto M: Molecular pathogenesis of hepatocellular carcinoma: altering transforming growth factor- $\beta$ signaling in hepatocarcinogenesis. Dig Dis 29: 284-288, 2011.

4. Rong M, Chen G and Dang Y: Increased miR-221 expression in hepatocellular carcinoma tissues and its role in enhancing cell growth and inhibiting apoptosis in vitro. BMC Cancer 13: 21, 2013.

5. Zou C, Li Y, Cao Y, Zhang J, Jiang J, Sheng Y, Wang S, Huang A and Tang H: Up-regulated MicroRNA-181a induces carcinogenesis in Hepatitis B virus-related hepatocellular carcinoma by targeting E2F5. BMC Cancer 14: 97, 2014.

6. Su ZX, Zhao J, Rong ZH, Geng WM, Wu YG and Qin CK: Upregulation of microRNA-25 associates with prognosis in hepatocellular carcinoma. Diagn Pathol 9: 47, 2014.

7. Wang L, Yao J, Shi X, Hu L, Li Z, Song T and Huang C: MicroRNA-302b suppresses cell proliferation by targeting EGFR in human hepatocellular carcinoma SMMC-7721 cells. BMC Cancer 13: 448, 2013.

8. Aravalli RN, Steer CJ and Cressman EN: Molecular mechanisms of hepatocellular carcinoma. Hepatology 48: 2047-2063, 2008.

9. Thorgeirsson SS, Lee JS and Grisham JW: Functional genomics of hepatocellular carcinoma. Hepatology 43 (2 Suppl 1): S145-S150, 2006.

10. Villanueva A, Newell P, Chiang DY, Friedman SL and Llovet JM: Genomics and signaling pathways in hepatocellular carcinoma. Semin Liver Dis 27: 55-76, 2007.

11. Roessler S, Budhu A and Wang XW: Deciphering cancer heterogeneity: the biological space. Front Cell Dev Biol 2: 12, 2014

12. Shirasaki T, Honda M, Shimakami T, Horii R, Yamashita T, Sakai Y, Sakai A, Okada H, Watanabe R, Murakami S, et al: MicroRNA-27a regulates lipid metabolism and inhibits hepatitis $\mathrm{C}$ virus replication in human hepatoma cells. J Virol 87 : 5270-5286, 2013.

13. Lee RC, Feinbaum RL and Ambros V: The C. elegans heterochronic gene lin- 4 encodes small RNAs with antisense complementarity to lin-14. Cell 75: 843-854, 1993.

14. Friedman RC, Farh KK, Burge CB and Bartel DP: Most mammalian mRNAs are conserved targets of microRNAs. Genome Res 19: 92-105, 2009.

15. Wu D, Ding J, Wang L, Pan H, Zhou Z, Zhou J and Qu P: microRNA-125b inhibits cell migration and invasion by targeting matrix metallopeptidase 13 in bladder cancer. Oncol Lett 5: 829-834, 2013.

16. Bartel DP: MicroRNAs: target recognition and regulatory functions. Cell 136: 215-233, 2009.

17. Ghildiyal $M$ and Zamore PD: Small silencing RNAs: an expanding universe. Nat Rev Genet 10: 94-108, 2009.

18. Bartel DP: MicroRNAs: genomics, biogenesis, mechanism, and function. Cell 116: 281-297, 2004.

19. Ambros V: The functions of animal microRNAs. Nature 431: 350-355, 2004.

20. Takahashi RU, Makiko O and Ochiya T: Role of microRNA in cancer development: biology and clinical applications. Nihon Geka Gakkai Zasshi 113: 197-203, 2012 (In Japanese).

21. Farazi TA, Hoell JI, Morozov P and Tuschl T: MicroRNAs in human cancer. Adv Exp Med Biol 774: 1-20, 2013.

22. Ura S, Honda M, Yamashita T, Ueda T, Takatori H, Nishino R, Sunakozaka H, Sakai Y, Horimoto K and Kaneko S: Differential microRNA expression between hepatitis B and hepatitis Cleading disease progression to hepatocellular carcinoma. Hepatology 49: 1098-1112, 2009.

23. Ventura A and Jacks T: MicroRNAs and cancer: short RNAs go a long way. Cell 136: 586-591, 2009.

24. Wu D, Zhou Y, Pan H, Zhou J, Fan J and Qu P: microRNA-99a inhibiting cell proliferation, migration and invasion by targeting fibroblast growth factor receptor 3 in bladder cancer. Oncol Lett 7: 1219-1224, 2014 
25. Zhou Y, Wu D, Tao J, Qu P, Zhou Z and Hou J: MicroRNA-133 inhibits cell proliferation, migration and invasion by targeting epidermal growth factor receptor and its downstream effector proteins in bladder cancer. Scand J Urol 47: 423-432, 2013.

26. Kawakami K, Enokida H, Chiyomaru T, Tatarano S, Yoshino H, Kagara I, Gotanda T, Tachiwada T, Nishiyama K, Nohata N, et al: The functional significance of miR-1 and miR-133a in renal cell carcinoma. Eur J Cancer 48: 827-836, 2012.

27. Kano M, Seki N, Kikkawa N, Fujimura L, Hoshino I, Akutsu Y, Chiyomaru T, Enokida H, Nakagawa $M$ and Matsubara $H$ : miR-145, miR-133a and miR-133b: Tumor-suppressive miRNAs target FSCN1 in esophageal squamous cell carcinoma. Int J Cancer 127: 2804-2814, 2010.

28. Chiyomaru T, Enokida H, Tatarano S, Kawahara K, Uchida Y, Nishiyama K, Fujimura L, Kikkawa N, Seki N and Nakagawa M: miR-145 and miR-133a function as tumour suppressors and directly regulate FSCN1 expression in bladder cancer. Br J Cancer 102: 883-891, 2010.

29. Ruebel K, Leontovich AA, Stilling GA, Zhang S, Righi A, Jin L and Lloyd RV: MicroRNA expression in ileal carcinoid tumors: downregulation of microRNA-133a with tumor progression. Mod Pathol 23: 367-375, 2010.

30. Rao PK, Missiaglia E, Shields L, Hyde G, Yuan B, Shepherd CJ, Shipley J and Lodish HF: Distinct roles for miR-1 and miR-133a in the proliferation and differentiation of rhabdomyosarcoma cells. FASEB J 24: 3427-3437, 2010

31. Chomczynski P and Sacchi N: The single-step method of RNA isolation by acid guanidinium thiocyanate-phenol-chloroform extraction: twenty-something years on. Nature Protoc 1: 581-585, 2006.

32. Tao J, Lu Q, Wu D, Li P, Xu B, Qing W, Wang M, Zhang Z and Zhang W: microRNA-21 modulates cell proliferation and sensitivity to doxorubicin in bladder cancer cells. Oncol Rep 25 $1721-1729,2011$

33. Dong DL, Chen C, Huo R, Wang N, Li Z, Tu YJ, Hu JT, Chu X, Huang W and Yang BF: Reciprocal repression between microRNA-133 and calcineurin regulates cardiac hypertrophy: a novel mechanism for progressive cardiac hypertrophy. Hypertension 55: 946-952, 2010

34. Tao J, Wu D, Xu B, Qian W, Li P, Lu Q, Yin C and Zhang W: microRNA-133 inhibits cell proliferation, migration and invasion in prostate cancer cells by targeting the epidermal growth factor receptor. Oncol Rep 27: 1967-1975, 2012.

35. Rao PK, Kumar RM, Farkhondeh M, Baskerville S and Lodish HF: Myogenic factors that regulate expression of muscle-specific microRNAs. Proc Nat Acad Sci USA 103: 8721-8726, 2006.

36. Bostjancic E, Zidar N, Stajer D and Glavac D: MicroRNAs miR-1, miR-133a, miR-133b and miR-208 are dysregulated in human myocardial infarction. Cardiology 115: 163-169, 2010.

37. Uchida Y, Chiyomaru T, Enokida H, Kawakami K, Tatarano S, Kawahara K, Nishiyama K, Seki N and Nakagawa M: MiR-133a induces apoptosis through direct regulation of GSTP1 in bladder cancer cell lines. Urol Oncol 31: 115-123, 2013.

38. Chiyomaru T, Enokida H, Kawakami K, Tatarano S, Uchida Y, Kawahara K, Nishiyama K, Seki N and Nakagawa M: Functional role of LASP1 in cell viability and its regulation by microRNAs in bladder cancer. Urol Oncol 30: 434-443, 2012.

39. Ferlay J, Shin HR, Bray F, Forman D, Mathers C and Parkin DM: Estimates of worldwide burden of cancer in 2008: GLOBOCAN 2008. Int J Cancer 127: 2893-2917, 2010.
40. Han X, Yan DM, Zhao XF, Matsuura H, Ding WG, Li P, Jiang S, Du BR, Du PG and Zhu X: GHGKHKNK octapeptide (P-5m) inhibits metastasis of HCCLM3 cell lines via regulation of MMP-2 expression in in vitro and in vivo studies. Molecules 17: 1357-1372, 2012

41. Lou L, Chen YX, Jin L, Li X, Tao X, Zhu J, Chen X, Wu S, Ye W, He J, et al: Enhancement of invasion of hepatocellular carcinoma cells through lysophosphatidic acid receptor. J Int Med Res 41: $55-63,2013$.

42. Sun MH, Han XC, Jia MK, Jiang WD, Wang M, Zhang H, Han G and Jiang Y: Expressions of inducible nitric oxide synthase and matrix metalloproteinase-9 and their effects on angiogenesis and progression of hepatocellular carcinoma. W J Gastroenterol 11: 5931-5937, 2005

43. Verma S, Kesh K, Ganguly N, Jana S and Swarnakar S: Matrix metalloproteinases and gastrointestinal cancers: Impacts of dietary antioxidants. World J Biol Chem 5: 355-376, 2014.

44. Kallakury BV, Karikehalli S, Haholu A, Sheehan CE, Azumi N and Ross JS: Increased expression of matrix metalloproteinases 2 and 9 and tissue inhibitors of metalloproteinases 1 and 2 correlate with poor prognostic variables in renal cell carcinoma. Clin Cancer Res 7: 3113-3119, 2001.

45. Morgia G, Falsaperla M, Malaponte G, Madonia M, Indelicato M, Travali S and Mazzarino MC: Matrix metalloproteinases as diagnostic (MMP-13) and prognostic (MMP-2, MMP-9) markers of prostate cancer. Urol Res 33: 44-50, 2005.

46. Gao ZH, Tretiakova MS, Liu WH, Gong C, Farris PD and Hart J: Association of E-cadherin, matrix metalloproteinases, and tissue inhibitors of metalloproteinases with the progression and metastasis of hepatocellular carcinoma. Mod Pathol 19: 533-540, 2006.

47. Jang JW, Park ST, Kwon JH, You CR, Choi JY, Jung CK, Bae SH and Yoon SK: Suppression of hepatic tumor growth and metastasis by metronomic therapy in a rat model of hepatocellular carcinoma. Exp Mol Med 43: 305-312, 2011.

48. Xiang ZL, Zeng ZC, Fan J, Tang ZY, Zeng HY and Gao DM: Gene expression profiling of fixed tissues identified hypoxia-inducible factor-1alpha, VEGF, and matrix metalloproteinase-2 as biomarkers of lymph node metastasis in hepatocellular carcinoma. Clin Cancer Res 17: 5463-5472, 2011.

49. Chen R, Cui J, Xu C, Xue T, Guo K, Gao D, Liu Y, Ye S and Ren Z: The significance of MMP-9 over MMP-2 in HCC invasiveness and recurrence of hepatocellular carcinoma after curative resection. Ann Surg Oncol 19 Suppl 3: S375-S384, 2012.

50. Hong S, Park KK, Magae J, Ando K, Lee TS, Kwon TK, Kwak JY, Kim CH and Chang YC: Ascochlorin inhibits matrix metalloproteinase- 9 expression by suppressing activator protein-1-mediated gene expression through the ERK1/2 signaling pathway: inhibitory effects of ascochlorin on the invasion of renal carcinoma cells. J Biol Chem 280: 25202-25209, 2005.

51. Santhekadur PK, Gredler R, Chen D, Siddiq A, Shen XN, Das SK, Emdad L, Fisher PB and Sarkar D: Late SV40 factor (LSF) enhances angiogenesis by transcriptionally up-regulating matrix metalloproteinase-9 (MMP-9). J Biol Chem 287: 3425-3432, 2012.

52. Jiang YF, Yang ZH and Hu JQ: Recurrence or metastasis of HCC: predictors, early detection and experimental antiangiogenic therapy. World J Gastroenterol 6: 61-65, 2000.

53. Hayasaka A, Suzuki N, Fujimoto N, Iwama S, Fukuyama E, Kanda Y and Saisho H: Elevated plasma levels of matrix metalloproteinase-9 (92-kd type IV collagenase/gelatinase B) in hepatocellular carcinoma. Hepatology 24: 1058-1062, 1996. 